\title{
The use of mobile phone functionalities by patients with asthma and their desire to use for self-care purposes
}

\author{
Ehsan Nabovati ${ }^{1}$, Mehrdad Farzandipour ${ }^{1}$, Marzieh Heidarzadeh Arani ${ }^{2}$, Hossein Akbari ${ }^{3}$, Reihane Sharif ${ }^{*}$ (i) \\ and Shima Anvari ${ }^{1}$
}

\begin{abstract}
Background: Mobile health (mHealth) has good potential for promoting self-care in patients suffering from chronic diseases. The patients' positive attitude toward this technology is a key factor for the successful implementation. The present study was conducted to investigate the asthma patients' use of mobile phone functionalities and their desire to receive self-care services through this technology.
\end{abstract}

Methods: This survey study was conducted in Iran in 2018. The study population consisted of 146 patients suffering from asthma. The data collection tool was a questionnaire containing items on the demographic characteristics of patients, current use of mobile phone functionalities, and desire to use them for receiving self-care services. Data were analyzed using descriptive and analytical statistics.

Results: Out of the 160 questionnaires distributed, 146 (91.25\%) were completed. The majority of the participants had smartphones (84.9\%). Less than half of the participants occasionally used mobile phone functionalities including mobile phone calls (42.5\%) and mobile Internet (40.4\%) to receive asthma-related information. A significant number of the participants had never used smartphone applications (72.6\%) and E-mail (66.4\%) to receive asthma-related information. The participants had their greatest use of Internet search, followed by social media, to receive information about asthma symptoms, allergenic and irritating substances, medicinal therapy, and how to use therapy aids. The participants were most willing to use social media for receiving asthma information, communicating with other patients, receiving reminders about doctor's appointment, and receiving warnings about the lack of asthma control.

Conclusion: In Iran as a developing country, asthma patients use Internet search mostly to receive instructional information and are willing to use social media rather than other mobile phone functionalities to receive self-care services. These patients believe that mobile phones are appropriate for receiving instructional information and reminders.

Keywords: Asthma, mHealth, Mobile phone, Self-care

*Correspondence: Fr.sharif@yahoo.com

${ }^{1}$ Health Information Management Research Center, Department of Health Information Management and Technology, School of Allied Health Professions, Kashan University of Medical Sciences, Pezeshk Blvd, 5th of Qotbe Ravandi Blvd - Pardis Daneshgah, Kashan, Iran

Full list of author information is available at the end of the article

\section{Background}

Asthma is a chronic and common disease of the airways that affects more than 339 million people globally in 2016 [1]. According to WHO estimates, there were 417,918 deaths due to asthma at the global level and 24.8 million disability-adjusted life years (DALYs) attributable to Asthma in 2016 [2,3]. Despite the extensive use of evidence-based guidelines and available

(c) The Author(s) 2020. Open Access This article is licensed under a Creative Commons Attribution 4.0 International License, which permits use, sharing, adaptation, distribution and reproduction in any medium or format, as long as you give appropriate credit to the original author(s) and the source, provide a link to the Creative Commons licence, and indicate if changes were made. The images or other third party material in this article are included in the article's Creative Commons licence, unless indicated otherwise in a credit line to the material. If material is not included in the article's Creative Commons licence and your intended use is not permitted by statutory regulation or exceeds the permitted use, you will need to obtain permission directly from the copyright holder. To view a copy of this licence, visit http://creativecommons.org/licenses/by/4.0/. The Creative Commons Public Domain Dedication waiver (http://creativeco mmons.org/publicdomain/zero/1.0/) applies to the data made available in this article, unless otherwise stated in a credit line to the data. 
therapy options, symptoms of asthma have not been controlled in patients with asthma effectively [4-6], so that almost $50 \%$ of them have symptoms more than once a week $[7,8]$. There is much evidence that selfcare by patients with asthma have beneficial outcomes, including reduced hospital stays, better pulmonary function, reduced symptoms, and general compliance with treatments [9-11].

One of the approaches for promoting self-care skills in patients with asthma is to provide self-care services (i.e., providing basic information about the nature of asthma, avoiding exposure to allergen and triggers, treating with drugs, providing alerts and reminders to patients, and how to use the therapeutic tools [12]) through information technology tools (e.g. the Internet, mobile phones, and computer software). Given the increasing worldwide use of smartphones, mobile health (mHealth) technologies can work as promising tools to improve self-care in patients with asthma by providing support services such as communication information, providing learning materials, and sending reminders for behavior change $[13,14]$. mHealth, as a component of electronic health, is related to the use of mobile phones and other wireless technologies to improve the provision of health-related services. Evidence shows that mHealth tools, including short message service (SMS), applications (apps) and other related technologies, provide a good opportunity for improving patient communications and health care provision [1520]. Moreover, ease of use, portability and ubiquity in all regions are the potential benefits of mHealth tools for the prevention, diagnosis, treatment and care of diseases and also increasing the access to health services and reducing the costs incurred [21].

There is limited evidence on the efficacy of mHealth in terms of asthma self-care. Two studies showed the positive effect of these interventions on the quality of life, symptoms of disease, and adherence to treatment in patients with asthma [22, 23]. Nevertheless, a study conducted by Ryan et al. (2012) found that using mobile phone apps had no significant effects on asthma selfcare outcomes [24]. One of the key factors for successful implementation of mHealth interventions for improving patients' self-care is considering their attitude toward these technologies $[19,25]$. Based on the studies, two studies were conducted in developed countries in this field, both of which showed a positive attitude of patients with asthma toward modern technologies, including mobile phones, SMS, Internet and E-mail, but they also had concerns about the use of these technologies including its time-consuming nature and costs $[26,27]$. This indicates the lack of studies in this field and especially its absence in developing countries. Therefore, further studies on the use of mobile phone functionalities by patients with asthma and their desire to use for self-care purposes, especially in developing countries, are necessary.

Given that no similar studies have yet been conducted in developing countries on asthma patients' use of and willingness to use mobile phone functionalities to receive self-care services, the present study was aimed to investigate the patients' current use of mobile phone functionalities (i.e. phone calls, SMS, apps, Internet browsing, E-mail, and social media) to receive self-care services and their willingness to use these functionalities. Understanding these aspects will contribute to the design and implementation of mHealth interventions to help promote self-care in patients with asthma.

\section{Methods}

\section{Study design, setting and population}

This survey study was conducted in Iran in 2018 to investigate asthma patients' use of and desire to use mobile phone functionalities to support self-care. The study population consisted of patients with asthma referred to the only allergy and asthma clinic in Kashan, Iran, with at least one year since the confirmation of their asthma diagnosis and who owned a mobile phone and had at least a high school diploma. In a similar study conducted by Pinnock et al. [26], the mean and standard deviation (SD) of the total score of mobile phone use by patients with asthma was $7.1 \pm 2.4$, and considering a confidence interval of $95 \%$ and the accuracy of 0.4 in estimating the mean score, the minimum required sample size was calculated as 138 patients.

\section{Questionnaire}

To collect data, relevant literature was reviewed and then a questionnaire was designed according to the views expressed by experts about asthma-related information (from asthma and allergy subspecialists) and also about mobile phone functionalities (from health information management and medical informatics experts). To determine the face validity, the questionnaire was first distributed among two health information management and medical informatics experts and its face validity was approved. The content validity of the questionnaire was assessed by 12 experts (in health information management, medical informatics, and allergy and asthma specialization). The validity of each item (i.e. relevance and clarity) plus the validity index of the entire tool (i.e. comprehensiveness) were determined based on a Likert scale (from 1 ='unfavorable' to $4=$ 'totally favorable'). The content validity of each item was assessed based on the content validity index (CVI), and if less than 0.7 , the item was revised and modified. The content validity ratio (CVR) was also determined based on Lawshe's Table [28] and the items with values less than 0.56 were eliminated. 
The reliability of the questionnaire was determined by the split-half method and its Cronbach's alpha was 0.88 .

Following the validation of the instrument, the resultant questionnaire had 38 items in three main sections: demographic information (seven items), overall use of mobile phone functionalities (20 items) and, desire to use mobile phone functionalities (11 items) (Additional file 1). Out of these, five items had "Yes" and "No" answers. A "Yes" answer scored one point and a "No" answer zero points, and six items were four-choice questions, with 'everyday' $=1$ point, 'several times per week' $=0.6$, 'occasionally' $=0.3$ and 'never' $=0$. The items on the current patients' use from overall use of mobile phone functionalities (ten items) and the patients' desire to use (ten items) were scored such that using or the desire to use each functionality were given one point, and no use or no desire to use were given zero points. The sum of the scores from the two sections of the questionnaire (i.e. use of and desire to use) were categorized into three groups as low, medium or high based on 25th and 75 th percentiles.

\section{Data collection}

Samples were selected using convenience sampling method [29]. To collect data, the researcher visited the allergy and asthma clinic. Before completing the questionnaire, the eligible patients signed informed consent forms, in which they were briefed on the study objectives and their voluntary participation in the study and the anonymity and confidentiality of their information were ensured; accordingly, their scores were used through coding. Participants completed the self-report questionnaire while waiting to see their physician and any ambiguities in the answers were resolved by asking questions from the respondent. Out of 160 questionnaires distributed among patients with asthma referred to the allergy and asthma clinic, 146 patients participated in the study.

\section{Statistical analysis}

Data were analyzed in Statistical Package for the Social Sciences (SPSS) 22 (IBM SPSS Statistics, IBM Corporation, Armonk, NY, USA). First, the number and frequency percentage of the demographic variables, accessibility and use of mobile phone functionalities were calculated. Then, the mean and standard deviation of the quantitative variables as well as the frequency of the patients' use and desire to use were calculated in terms of the demographic variables. The sum of the scores of the two sections (i.e. use and desire to use) was then calculated. Based on the 25th and 75th percentiles, patients were categorized into three groups in terms of their rate of use: 'low' (scores <12), 'moderate' (scores of 12-15.92) and 'high' (scores $>15.92$ ). Also, in terms of their desire to use, patients were categorized as 'low' (scores $<11$ ), 'moderate' (scores of 11-15), and 'high' (scores of $>15$ ). The maximum score that could be obtained in two different groups (i.e. use and desire to use) were, respectively, 80 and 71 . Frequency percentage was also calculated for each of the items. The relationships between the demographic variables and the questionnaire sections (i.e. use and desire to use) were assessed using the Chi-square or Fisher's exact tests. $P<0.05$ was taken as the level of statistical significance.

\section{Results \\ Participants' characteristics}

In this study, 160 questionnaires were distributed among the participants, of which 146 were willing to complete the questionnaire, with a response rate of $91.25 \%$. Of the 146 participating patients with asthma, 91 (62.3\%) were female. Participants' mean age was $34.4 \pm 13.3$ years. A total of 81 patients $(55.5 \%)$ had higher than bachelor's degree and 144 (98.6\%) lived in city. A total of 119 patients $(81.5 \%)$ had asthma for nine years or less. In terms of the severity of asthma, $42.5 \%$ of the participants had the "mild persistent" type, 30.1\% "moderate persistent", 9.6\% "severe persistent" and 4.8\% "intermittent" asthma (Table 1).

Table 2 presents the general findings regarding the asthma patients' use and desire to use mobile phone. Out of the 146 participants, 90 (61.6\%) used mobile phones to receive asthma care services, $125(85.6 \%)$ had access to the Internet through mobile phone, $124(84.9 \%)$ had smartphones, and $24(16.4 \%)$ had at least one asthmarelated app on their mobile phone. Overall, 127 patients (87\%) were willing to use mobile phones to receive asthma-care services.

Table 3 demonstrates the asthma patients' use of mobile phone functionalities to receive asthma-related information in four categories, namely every day, several times per week, occasionally, and never. The results showed that the majority of the patients have never used any mobile phone functionalities to receive asthmarelated information; however, they occasionally used mobile phone calls $(42.5 \%)$ and SMS (36.3\%) to receive information and used their mobile Internet (40.4\%), social media (39\%) and apps (22.6\%) to search for and access asthma-related information, and also used E-mail services on their mobile phone to communicate with others $(26.7 \%)$.

The results showed that the participants had made their greatest use of the Internet search for the purpose of receiving information about asthma warning symptoms and allergenic and irritating substances (43.2\%), medicinal therapy (39.7\%) and how to use therapy aids (35.6\%). The participants had made their greatest use of social 
Table 1 Participants' demographic information $(\mathrm{N}=146)$

\begin{tabular}{|c|c|c|}
\hline Demographic variable & Frequency & Percentage \\
\hline \multicolumn{3}{|l|}{ Gender } \\
\hline Female & 91 & 62.3 \\
\hline Male & 55 & 37.7 \\
\hline \multicolumn{3}{|l|}{ Age (years) } \\
\hline 25 and younger & 48 & 32.9 \\
\hline $25-45$ & 67 & 45.9 \\
\hline 45 and above & 31 & 21.2 \\
\hline Mean $\pm S D^{a}$ & $34.4 \pm 13.3$ & \\
\hline \multicolumn{3}{|l|}{ Education level } \\
\hline Bachelor's degree or less & 65 & 44.5 \\
\hline Higher than bachelor's degree & 81 & 55.5 \\
\hline \multicolumn{3}{|l|}{ Place of residence } \\
\hline City & 144 & 98.6 \\
\hline Village & 2 & 1.4 \\
\hline \multicolumn{3}{|l|}{ Duration of asthma } \\
\hline 9 years or less & 119 & 81.5 \\
\hline More than 9 years & 27 & 18.5 \\
\hline Mean $\pm S D$ & $4.97 \pm 4.594$ & \\
\hline \multicolumn{3}{|l|}{ Severity of asthma ${ }^{b}$} \\
\hline Mild persistent & 62 & 42.5 \\
\hline Moderate persistent & 44 & 30.1 \\
\hline Severe persistent & 14 & 9.6 \\
\hline Intermittent & 7 & 4.8 \\
\hline Not known & 19 & 13 \\
\hline
\end{tabular}

a Standard Deviation (SD)

${ }^{b}$ Classified according to the Expert Panel Report 3 (EPR-3): Guidelines for the Diagnosis and Management of Asthma [30]

media for receiving reminders about the peak expiratory flow (PEF) test (52.1\%), communicating with other patients (34.9\%), being warned about the lack of asthma control and being reminded of taking medications on time $(32.9 \%)$, and being reminded of their vaccination schedule and doctor or nurse appointments (31.5\%). Meanwhile, the patients with asthma had a greater desire to use social media (compared to the other functionalities of mobile phones) for receiving information about asthma warning symptoms (54.1\%), medicinal therapy (54.1\%), allergenic and irritating substances (54.1\%) and how to use therapy aids (52.1\%). Moreover, $56.8 \%$ of the participants were willing to use social media to communicate with other patients, $50.7 \%$ to be reminded of their appointments with the doctor or nurse and vaccination schedule, $52.4 \%$ to be reminded of taking medications on time, $52.1 \%$ to be reminded of taking the PEF test, and $52.7 \%$ to be warned about the lack of asthma control (Additional file 2). The results showed that education level, place of residence, severity of asthma, and duration with asthma had no significant relationships with the patients' use of mobile phone functionalities or their views about this technology (Additional file 3).

\section{Discussion}

Principal findings

The majority of the participants in this study had smartphones and access to the Internet on their mobile phones. Almost half of the participants occasionally used mobile phone calls and mobile Internet to receive asthma-related information. A significant number of the patients had never used mobile phone apps or E-mails to receive asthma-related information. The patients had made their greatest use of mobile phone functionalities through the Internet search, followed by social media, for the purpose of receiving information about asthma warning symptoms and allergenic and irritating substances, medicinal therapy and how to use therapy aids. The participants were most willing to use social media to receive information, communicate with other patients and be reminded of their doctor's appointments, and warned about their lack of asthma control.

The present findings showed that a significant number of the patients had Internet access on their mobile phones, which agrees with the results of other studies on the access of patients with asthma (2017) [31], pregnant women (2014) [32] and African-American families (2014) [33] to the Internet. In contrast, a Pew Research Center report found that Internet access rates among African-Americans were relatively low [34]. Due to recent technological advances, there has been

Table 2 Overall use of and desire to use mobile phone functionalities by the asthma patients $(N=146)$

\begin{tabular}{lcr}
\hline Items & \multicolumn{1}{l}{ Number (\%) } & No \\
\cline { 2 - 3 } & \multicolumn{1}{l}{ Yes } & $56(38.4)$ \\
\hline Use of mobile phones to receive asthma care services & $90(61.6)$ & $21(14.4)$ \\
Mobile Internet access & $125(85.6)$ & $22(15.1)$ \\
Have smart mobile phone (ability to install apps) & $124(84.9)$ & 122(83.6) \\
Installing mobile apps related to asthma care & $124(16.4)$ & $19(13)$ \\
Desire to use mobile phones to receive asthma care services & $127(87)$ & \\
\hline
\end{tabular}


Table 3 The frequency of use of mobile phone functionalities by the asthma patients $(N=146)$

\begin{tabular}{|c|c|c|c|c|}
\hline Items & Everyday (\%) & $\begin{array}{l}\text { Several } \\
\text { times per week } \\
(\%)\end{array}$ & Occasionally $^{\mathrm{a}}(\%)$ & Never (\%) \\
\hline $\begin{array}{l}\text { Receiving asthma-related information through mobile phone calls (to friends, rela- } \\
\text { tives, doctors and nurses) }\end{array}$ & $3(2)$ & $7(4.8)$ & $62(42.5)$ & $74(50.7)$ \\
\hline $\begin{array}{l}\text { Receiving asthma-related information through SMS (to friends, relatives, doctors } \\
\text { and nurses) }\end{array}$ & $1(0.7)$ & $7(4.8)$ & $53(36.3)$ & $85(58.2)$ \\
\hline Using mobile Internet to search for asthma-related information & $1(0.7)$ & $22(15.1)$ & $59(40.4)$ & $64(43.8)$ \\
\hline $\begin{array}{l}\text { Using social media (such as Telegram channels) to access asthma-related informa- } \\
\text { tion }\end{array}$ & $4(2.7)$ & $18(12.3)$ & $57(39)$ & $67(45.9)$ \\
\hline $\begin{array}{l}\text { Using mobile E-mail to communicate with others (friends, relatives, doctors and } \\
\text { nurses) to receive asthma-related information }\end{array}$ & 0 & $10(6.9)$ & $39(26.7)$ & $97(66.4)$ \\
\hline Using of apps (software) to access asthma-related information & $2(1.4)$ & $5(3.4)$ & $33(22.6)$ & $106(72.6)$ \\
\hline
\end{tabular}

a About once a week

a significant increase in the use of mobile technologies and Internet access. So that areas with low Internet access are also increasing [35]. Therefore, the availability of these tools provides new mechanisms for providing self-care for chronic diseases such as asthma. In addition, the majority of the participants in the present study were willing to use their mobile phones to receive asthma care services. Similarly, Fonseca et al. [36], reported in a study that a large majority of patients were willing and ready to use communication technologies such as cell phones and the web to help them manage their asthma. In another study, the most important reason for patients' desire to use mobile phone technologies was to save time and engaging patients in their disease management [37]. But in general, to successfully introduce new technologies to patients, their concerns must be addressed and patients must be confident about the benefits of using such technologies.

The results showed that less than half of the participants occasionally used mobile phone calls and the Internet to receive asthma-related information. Similarly, Van de Belt et al. (2013) [38] argued that less than half of Dutch people conducted online search for health-related information occasionally before visiting their doctors and after consulting with the doctor. Also, in a study by Calderón et al. (2017) [31], less than half of patients with asthma used the Internet to seek information about asthma. Despite the potential benefits of searching for health information on the Internet, many patients have raised concerns about the negative effects of this searched health information on the Internet. Therefore, the low quality of information available on the Internet can be stated as one of the reasons for patients' low use of Internet health information seeking, which can lead to patients being misinformed, lead to distress, and increase the tendency towards selfdiagnosis or self-treatment [39].

The results of one study showed that $77.3 \%$ of patients with asthma used E-mails at least once a week, and E-mail was the only platform through which most of them were interested in receiving information and communicating with physicians [40]. However, in the present study, patients' non-use of E-mail communication may be due to their lack of knowledge about using this feature to communicate, lack of an E-mail account, delay in receiving a response, and a lack of sufficient time for physicians to respond. The results of the study conducted by Singh et al. (in New York 2014) [41] concur with the present study findings in terms of the degree of mobile app usage. They reported that although the majority of adolescents or their caregivers were willing to use mobile health apps, only $26 \%$ of them had health-related apps installed, and their feedback revealed that the lack of knowledge, poor finances, and privacy concerns were barriers for downloading or using medical apps. Therefore, it seems necessary for physicians to carefully review the information content of the mobile app, before introducing it to their patients.

In the present study, the participants had their greatest use of mobile phone functionalities through the Internet search, followed by social media, to receive asthma-related information, which agrees with the results of other studies [32, 38, 42, 43]. A systematic review study reported that most pregnant women used the Internet as a source of information [44], while in a recent study, patients with asthma preferred SMS over the Internet search and social media, and their reasons for this preference were the low costs and reliability of SMS [31]. In another study, Chisolm et al. [45] analyzed the potential reasons for asthma and diabetes patients' 
use or lack of use of the Internet, and proposed the lack of time, interest, access and medical necessity as the reasons for not using the Internet, and argued that the reasons for using the Internet were its usefulness, ease of use, medical necessity, and up-to-date nature. In that study, health literacy and demographic factors were significantly linked to the Internet use. Considering that the Internet and social media technologies, in particular, are an important source of health information and the use of online social groups is also increasing, therefore, patients can use these technologies to share experiences and offer support to their peers.

In the present study, the patients were most willing to use social media for the purpose of receiving information, communicating with other patients, being reminded of doctor's appointments, and being warned about their lack of asthma control. Similarly, Ramirez et al. [46] reported that more than $70 \%$ of the patients in primary care clinics in Los Angeles were willing to use social media to communicate with other patients with similar problems. Calderón et al. [31] argued that young participants were inclined to use WhatsApp to receive information and be in direct contact with their doctor about asthma. Previous studies have shown how social media, such as Facebook and Twitter, have been effective in improving the outcomes of patients with chronic diseases such as human immunodeficiency virus (HIV), breast cancer and chronic tobacco use [47-49]. These studies demonstrated that social media encourage patients to share health information with others, to teach them about diseases and their treatment, and also to communicate with other patients with similar symptoms who are receiving similar therapies. Nevertheless, privacy concerns are often proposed as the barriers to use social media [50]. Like many emerging technologies, access to information must be controlled to address privacy concerns and safeguards must be put in place to reduce the risk of privacy breaches.

\section{Strength and limitations}

Based on the review of literature, the present study is the first to have been conducted in a developing country on asthma patients' use and desire to use all the functionalities of mobile phones for receiving self-care services. The results can provide a basis for future studies on the design and development of mobile health interventions for patients with asthma. The present study included a sample of 146 patients with asthma in one city, which may be considered as a limitation. Moreover, all the participants were selected from one medical center, since it was the only allergy and asthma clinic in the city of Kashan.

\section{Implications for practice and future research}

Given the evidence found regarding the willingness of patients with asthma to use mobile phone functionalities for receiving self-care services, the following measures are recommended for improving the acceptance of these tools. Clinical professionals should take into account the concerns of these patients about the quality of information provided through mobile phones and also give them assurances about the benefits of using these tools. In the present study, due to the lack of knowledge about asthma self-care apps and the lack of confidence in the informational content of these apps, the patients made little use of them. The cooperation of health care professionals appears necessary for the design, development, and implementation of these apps. The present study determined asthma patients' informational needs and their preferred types of functionalities for receiving asthma self-care services. Designing future interventions based on these informational needs thus appears imperative. Further studies are recommended on these patients' use of and desire to use mobile health technologies in larger populations.

\section{Conclusion}

Currently, patients with asthma often use the Internet search to receive information about asthma symptoms and allergenic and irritating substances, medicinal therapies and how to use therapy aids, and have a more positive attitude toward the use of social media compared to other mobile phone functionalities for receiving these services. Although the present study showed that the Internet and social media are preferred by patients with asthma for self-care, further studies should be conducted to evaluate the quality of asthmarelated information in these media.

\section{Supplementary information}

Supplementary information accompanies this paper at https://doi. org/10.1186/s12911-020-01301-z.

Additional file 1 English Questionnaire.

Additional file $\mathbf{2}$ The frequency of use and desire to use mobile phone functionalities for receiving information, as reminders and warnings in asthma patients $(\mathrm{N}=146)$.

Additional file $\mathbf{3}$ The frequency of use and desire to use mobile phone functionalities in asthma patients in terms of demographic variables $(\mathrm{N}=146)$.

\section{Abbreviations}

mHealth: Mobile Health; US: United States; SMS: Short message service; Apps: Applications; UK: United Kingdom; SD: Standard deviation; CVI: Content validity index; CVR: Content validity ratio; SPSS: Statistical Package for the Social Sciences; PEF: Peak expiratory flow; HIV: Human immunodeficiency virus. 


\section{Acknowledgements}

The authors would like to thank the experts who participated in the study. We would also like to extend our appreciation to the patients who participated in completing the questionnaire.

\section{Author contributions}

Conception and design of study (EN, MF), Development of materials (EN, MH, RSh), Data collection (RSh, ShA), Data analysis and interpretation (HA, RSh), Drafting the article (EN, RSh), Revising article critically for important intellectual content (EN, MF, RSh). All stages of this study, especially data collection and analysis, were conducted with the support of the funding body. All authors read and approved the final manuscript.

\section{Funding}

This study was supported by a grant from Kashan University of Medical Sciences Research Council (Number: 96105) and did not receive any grants from non-profit organizations and funding agencies in the public and commercial sectors.

\section{Availability of data and materials}

The datasets used and/or analysed during the current study available from the corresponding author on reasonable request.

\section{Ethics approval and consent to participate}

The research was approved by the Research Council and the Ethics Committee of Kashan University of Medical Sciences. The study was performed in compliance with the World Medical Association Declaration of Helsinki on Ethical Principles for Medical Research Involving Human Subjects, and Ethical approval was elicited from the Ethical Committee at the Kashan University of Medical Sciences (IR.KAUMS.NUHEPM.REC.1396.22). All participants were invited verbally to take part in the study. For those who agreed to participate, a signed written informed consent form was obtained.

\section{Consent for publication}

Not applicable.

\section{Competing interests}

The authors declare that they have no conflicts of interests.

\section{Author details}

${ }^{1}$ Health Information Management Research Center, Department of Health Information Management and Technology, School of Allied Health Professions, Kashan University of Medical Sciences, Pezeshk Blvd, 5th of Qotbe Ravandi Blvd - Pardis Daneshgah, Kashan, Iran. ${ }^{2}$ Pediatric Department, School of Medicine, Kashan University of Medical Sciences, Pezeshk Blvd, 5th of Qotbe Ravandi Blvd - Pardis Daneshgah, Kashan, Iran. ${ }^{3}$ Department of Biostatistics and Epidemiology, School of Health, Kashan University of Medical Sciences, Pezeshk Blvd, 5th of Qotbe Ravandi Blvd - Pardis Daneshgah, Kashan, Iran.

\section{Received: 9 May 2020 Accepted: 22 October 2020}

Published online: 30 October 2020

\section{References}

1. Vos T, Abajobir AA, Abate KH, Abbafati C, Abbas KM, Abd-Allah F, Abdulkader RS, Abdulle AM, Abebo TA, Abera SF. Global, regional, and national incidence, prevalence, and years lived with disability for 328 diseases and injuries for 195 countries, 1990-2016: a systematic analysis for the Global Burden of Disease Study 2016. The Lancet. 2017:390(10100):1211-59.

2. World Health Organisation. Global health estimates 2016: deaths by cause, age, sex, by country and by region, 2000-2016. Geneva: World Health Organization; 2018a.

3. World Health Organisation. Global health estimates 2016: disease burden by cause, age, sex, by country and by region, 2000-2016. Geneva: World Health Organization; 2018b.

4. Carlton BG, Lucas DO, Ellis EF, Conboy-Ellis K, Shoheiber O, Stempel DA. The status of asthma control and asthma prescribing practices in the United States: results of a large prospective asthma control survey of primary care practices. J Asthma. 2005;42(7):529-35. https://doi. org/10.1081/JAS-67000.

5. Schatz M, Mosen DM, Kosinski M, Vollmer WM, Magid DJ, O'Connor E, Zeiger RS. Predictors of asthma control in a random sample of asthmatic patients. J Asthma. 2007:44(4):341-5. https://doi.org/10.1080/02770 900701344421.

6. Vollmer WM, Markson LE, O'connor E, Ann Frazier E, Berger M, Buist AS. Association of asthma control with health care utilization: a prospective evaluation. Am J Resp Crit Care Med. 2002;165(2):195-9. https://doi. org/10.1164/ajrccm.165.2.2102127.

7. McDaniel MK, Waldfogel J. Racial and ethnic differences in the management of childhood asthma in the United States. J Asthma. 2012;49(8):785-91. https://doi.org/10.3109/02770903.2012.702840.

8. Adler RN, McBride J. Tools and strategies for improving asthma management. Fam Pract Manag. 2010;17(1):16.

9. Levy M, Andrews R, Buckingham R, Evans H, Francis C, Houston R, Lowe D, Nasser S, Paton J, Puri N. Why asthma still kills: the National Review of Asthma Deaths (NRAD). London: Royal College of Physcians; 2014.

10. James DR, Lyttle MD. British guideline on the management of asthma: SIGN Clinical Guideline 141, 2014. Arch Dis Child Educ Pract. 2016;101(6):319-22

11. Taylor SJ, Pinnock H, Epiphaniou E, Pearce G, Parke HL, Schwappach A, Purushotham N, Jacob S, Griffiths CJ, Greenhalgh T: A rapid synthesis of the evidence on interventions supporting self-management for people with long-term conditions: PRISMS-Practical systematic Review of SelfManagement Support for long-term conditions. Health Services and Delivery Research 2014, 2(53).

12. Farzandipour M, Nabovati E, Arani MH, Akbari H, Sharif R, Anvari S. Enhancing asthma patients' self-management through smartphonebased application: design, usability evaluation, and educational intervention. Appl Clin Inform. 2019:10(05):870-8. https://doi. org/10.1055/s-0039-1700866.

13. Schnall R, Mosley JP, Iribarren SJ, Bakken S, Carballo-Diéguez A, Brown W III. Comparison of a user-centered design, self-management app to existing mHealth apps for persons living with HIV. JMIR mHealth uHealth. 2015;3(3):e91. https://doi.org/10.2196/mhealth.4882.

14. Simpson AJ, Honkoop PJ, Kennington E, Snoeck-Stroband JB, Smith I, East J, Coleman C, Caress A, Chung KF, Sont JK. Perspectives of patients and healthcare professionals on mHealth for asthma self-management. Eur Respir J. 2017;49(5):1601966. https://doi.org/10.1183/13993003.01966 $-2016$.

15. Gurol-Urganci I, de Jongh T, Vodopivec-Jamsek V, Atun R, Car J. Mobile phone messaging reminders for attendance at healthcare appointments. Cochrane Database Syst Rev. 2013. https://doi.org/10.1002/14651858. CD007458.pub3.

16. de Jong CC, Ros WJ, Schrijvers G. The effects on health behavior and health outcomes of Internet-based asynchronous communication between health providers and patients with a chronic condition: a systematic review. J Med Internet Res. 2014;16(1):e19. https://doi. org/10.2196/jmir.3000.

17. De Jongh T, Gurol-Urganci I, Vodopivec-Jamsek V, Car J, Atun R. Mobile phone messaging for facilitating self-management of long-term illnesses. Cochrane Database Syst Rev. 2012. https://doi.org/10.1002/14651858. CD007459.pub2.

18. Grajales FJ III, Sheps S, Ho K, Novak-Lauscher H, Eysenbach G. Social media: a review and tutorial of applications in medicine and health care. $J$ Med Internet Res. 2014;16(2):e13. https://doi.org/10.2196/jmir.2912.

19. Jenssen BP, Mitra N, Shah A, Wan F, Grande D. Using digital technology to engage and communicate with patients: a survey of patient attitudes. J Gen Intern Med. 2016;31(1):85-92. https://doi.org/10.1007/s1160 6-015-3517-x.

20. Vodopivec-Jamsek V, de Jongh T, Gurol-Urganci I, Atun R, Car J. Mobile phone messaging for preventive health care. Cochrane Database Syst Rev. 2012. https://doi.org/10.1002/14651858.CD007457.pub2.

21. Park S, Burford S, Hanlen L, Dawda P, Dugdale P, Nolan C, Burns J. An integrated mHealth model for type 2 diabetes patients using mobile tablet devices. J Mob Technol Med. 2016;5(2):24-32. https://doi.org/10.7309/ jmtm.5.2.4.

22. Liu W-T, Huang C-D, Wang C-H, Lee K-Y, Lin S-M, Kuo H-P. A mobile telephone-based interactive self-care system improves asthma control. 
Eur Respir J. 2011;37(2):310-7. https://doi.org/10.1183/09031936.00000 810.

23. Farzandipour M, Nabovati E, Sharif R, Arani MH, Anvari S. Patient self-management of asthma using mobile health applications: a systematic review of the functionalities and effects. Appl Clin Inform. 2017;8(04):1068-81. https://doi.org/10.4338/ACl-2017-07-R-0116.

24. Ryan D, Price D, Musgrave SD, Malhotra S, Lee AJ, Ayansina D, Sheikh A, Tarassenko L, Pagliari C, Pinnock H. Clinical and cost effectiveness of mobile phone supported self monitoring of asthma: multicentre randomised controlled trial. BMJ. 2012;344:e1756. https://doi.org/10.1136/ bmj.e1756.

25. McGillicuddy JW, Weiland AK, Frenzel RM, Mueller M, Brunner-Jackson BM, Taber DJ, Baliga PK, Treiber FA. Patient attitudes toward mobile phonebased health monitoring: questionnaire study among kidney transplant recipients. J Med Internet Res. 2013;15(1):e6. https://doi.org/10.2196/ jmir.2284.

26. Pinnock H, Slack R, Pagliari C, Price D, Sheikh A. Professional and patient attitudes to using mobile phone technology to monitor asthma: questionnaire survey. Primary Care Respir J. 2006;15(4):237-45. https://doi. org/10.1016/j.pcrj.2006.03.001.

27. Hofstede J, de Bie J, Van Wijngaarden B, Heijmans M. Knowledge, use and attitude toward eHealth among patients with chronic lung diseases. Int J Med Inform. 2014;83(12):967-74. https://doi.org/10.1016/j.jmed inf.2014.08.011.

28. Lawshe CH. A quantitative approach to content validity. Pers Psychol. 1975;28(4):563-75.

29. Elfil M, Negida A. Sampling methods in clinical research; an educational review. Emergency. 2017;5(1):e52.

30. National AE, Prevention P. Expert Panel Report 3 (EPR-3): quidelines for the diagnosis and management of asthma-summary report 2007. J Allergy Clin Immunol. 2007;120(5 Suppl):S94

31. Calderón J, Cherrez A, Ramón GD, Jove OL, Baptist A, Matos E, Maciel BM, Calero E, Sanchez-Borges M, Cherrez S. Information and communication technology use in asthmatic patients: a cross-sectional study in Latin America. ERJ Open Res. 2017;3(3):00005-2017. https://doi. org/10.1183/23120541.00005-2017.

32. Waring ME, Simas TAM, Xiao RS, Lombardini LM, Allison JJ, Rosal MC Pagoto SL. Pregnant women's interest in a website or mobile application for healthy gestational weight gain. Sexual Reprod Healthc. 2014;5(4):182-4. https://doi.org/10.1016/j.srhc.2014.05.002.

33. Mitchell SJ, Godoy L, Shabazz K, Horn IB. Internet and mobile technology use among urban African American parents: survey study of a clinical population. J Med Internet Res. 2014;16(1):e9. https://doi.org/10.2196/ jmir.2673.

34. Duggan M, Rainie L. Cell phone activities. Washington, DC: Pew Research Center's Internet \& American Life Project; 2012.

35. Black T, Schwab-Reese L. Keeping up with the technology? Technological advances and child maltreatment research. Child Abuse Negl. 2018:85:185-6. https://doi.org/10.1016/j.chiabu.2018.04.006.

36. Fonseca J, Costa-Pereira A, Delgado L, Fernandes L, Castel-Branco M. ALLERGY Net. Allergy. 2006;61:389-90.

37. Tozzi AE, Carloni E, Gesualdo F, Russo L, Raponi M. Attitude of families of patients with genetic diseases to use $\mathrm{m}$-health technologies. Telemed e-Health. 2015;21 (2):86-9. https://doi.org/10.1089/tmj.2014.0080.
38. Van de Belt TH, Engelen LJ, Berben SA, Teerenstra S, Samsom M, Schoonhoven $L$. Internet and social media for health-related information and communication in health care: preferences of the Dutch general population. J Med Internet Res. 2013;15(10):e220. https://doi.org/10.2196/ jmir.2607.

39. Ahmad F, Hudak PL, Bercovitz K, Hollenberg E, Levinson W. Are physicians ready for patients with Internet-based health information? J Med Internet Res. 2006;8(3):e22. https://doi.org/10.2196/jmir.8.3.e22.

40. Baptist AP, Thompson M, Grossman KS, Mohammed L, Sy A, Sanders GM. Social media, text messaging, and email — preferences of asthma patients between 12 and 40 years old. J Asthma. 2011;48(8):824-30. https://doi. org/10.3109/02770903.2011.608460.

41. Singh A, Wilkinson S, Braganza S. Smartphones and pediatric apps to mobilize the medical home. J Pediatr. 2014;165(3):606-10. https://doi. org/10.1016/j.jpeds.2014.05.037.

42. Greaves RL, Wilkinson L, Orchard T. Accessing information on IBD: a survey of sources and reliability of internet resources. Gut. 2012;61:A396A396. https://doi.org/10.1136/gutjnl-2012-302514d.242.

43. Press VG, Wu M, Hull A, Kim E, Kim J, Meltzer DO, Arora V. Access and willingness to use technology for self-management at home among the general population versus patients with asthma or COPD. In: A37 the spectrum of COPD: epidemiology to outcomes. American Thoracic Society; 2017. p. A1396.

44. Sayakhot P, Carolan-Olah M. Internet use by pregnant women seeking pregnancy-related information: a systematic review. BMC Pregnancy Childbirth. 2016;16(1):65. https://doi.org/10.1 186/s12884-016-0856-5.

45. Chisolm DJ, Johnson LD, McAlearney AS. What makes teens start using and keep using health information web sites? A mixed model analysis of teens with chronic illnesses. Telemed e-Health. 2011;17(5):324-8. https:// doi.org/10.1089/tmj.2010.0165.

46. Ramirez V, Johnson E, Gonzalez C, Ramirez V, Rubino B, Rossetti G. Assessing the use of mobile health technology by patients: an observational study in primary care clinics. JMIR mHealth uHealth. 2016;4(2):e41. https ://doi.org/10.2196/mhealth.4928.

47. Abramson K, Keefe B, Chou W-YS. Communicating about cancer through Facebook: a qualitative analysis of a breast cancer awareness page. J Health Commun. 2015;20(2):237-43. https://doi.org/10.1080/10810 730.2014 .927034

48. Haines-Saah RJ, Kelly MT, Oliffe JL, Bottorff JL. Picture Me Smokefree: a qualitative study using social media and digital photography to engage young adults in tobacco reduction and cessation. J Med Internet Res. 2015;17(1):e27. https://doi.org/10.2196/jmir.4061.

49. Schnall R, Bakken S, Rojas M, Travers J, Carballo-Dieguez A. mHealth technology as a persuasive tool for treatment, care and management of persons living with HIV. AIDS Behav. 2015;19(2):81-9. https://doi. org/10.1007/s10461-014-0984-8.

50. Mattingly TJ II. Innovative patient care practices using social media. J Am Pharm Assoc. 2015;55(3):288-93. https://doi.org/10.1331/JAPhA .2015.14171.

\section{Publisher's Note}

Springer Nature remains neutral with regard to jurisdictional claims in published maps and institutional affiliations.

\footnotetext{
Ready to submit your research? Choose BMC and benefit from:

- fast, convenient online submission

- thorough peer review by experienced researchers in your field

- rapid publication on acceptance

- support for research data, including large and complex data types

- gold Open Access which fosters wider collaboration and increased citations

- maximum visibility for your research: over 100M website views per year
}

At BMC, research is always in progress.

Learn more biomedcentral.com/submissions 